\title{
An Application of Gas Chromatography-Mass Spectrometry (GC-MS) Fast Automated Scan/SIM Type (FASST) in Determining the Preservative Levels in Foods
}

\author{
Eman Wajeh Ammen ${ }^{1,2}$, Raghad Al-Salhi1 ${ }^{*}$ \\ ${ }^{1}$ Department of Chemistry, College of Science, University of Al-Mustansiriyah, Baghdad, Iraq \\ ${ }^{2}$ Directorate of Materials Research, Ministry of Science and Technology, Baghdad, Iraq \\ Email: *raghad.ahmed70@gmail.com
}

How to cite this paper: Ammen, E.W. and Al-Salhi, R. (2017) An Application of Gas Chromatography-Mass Spectrometry (GC-MS) Fast Automated Scan/SIM Type (FASST) in Determining the Preservative Levels in Foods. American Journal of Analytical Chemistry, 8, 307-316.

https://doi.org/10.4236/ajac.2017.85023

Received: April 17, 2017

Accepted: May 12, 2017

Published: May 15, 2017

Copyright ( $) 2017$ by authors and Scientific Research Publishing Inc. This work is licensed under the Creative Commons Attribution International License (CC BY 4.0).

http://creativecommons.org/licenses/by/4.0/ (c) (i) Open Access

\begin{abstract}
The preservatives used in food products are strictly monitored and regulated. The present study aims to imply a sensitive and reliable analytical method to quantify two classes of preservatives (i.e. carboxylic acid and phenolic compounds) in food by means of gas chromatography-mass spectrometry (GC-MS), aimed at monitoring the products available within the local stores. Target analytes were derivatized via aqueous-phase isobutyl chloroformate-mediated reaction followed by dispersive liquid-liquid microextraction (DLLME) method. The quantity and quality determination of the studied samples were assured by performing FASST approach in a single run GC-MS analysis. The combination of standard addition method with sample dilution compensated the effect of sample matrix on the quantitative determination of the tested preservatives in the examined samples. The concentrations of sorbic acid (SA) were $210 \mu \mathrm{g} / \mathrm{mL}$ and $1000 \mu \mathrm{g} / \mathrm{mL}$ in soft drink and sauces samples, respectively. On the other hand, sodium benzoate $(226 \mu \mathrm{g} / \mathrm{mL})$ was only found in soft drink, whereas, no parabens were detected in any samples collected from the local stores.
\end{abstract}

\section{Keywords}

Food, Preservatives, GC-MS, FASST Acquisition, Chloroformate

Derivatization, DLLME

\section{Introduction}

Preservatives are added to many food products such as soda, juices, and sauces 
to prevent decompositions resulting from microbial and alteration caused by chemical changes. The most commonly used global preservatives in food are SA, BA and their corresponding salts as well as parabens (properties of these preservatives are shown in Table 1) [1] [2]. Preservatives are added to extend the shelf life of unstable food products preventing the alteration in texture, flavour and color, as well as, to protect the health of consumers. However, adding high amount of preservatives could cause alteration in taste. Whereas, less than optimal amount will have little effect on microbial growth resulting in failure of preservative properties of the substance. Maximum levels for preservatives application in food products are subjected to international food law regulations [3] [4] [5] [6]. Therefore, an effective and efficient analytical method is required to assure that the amount of the added preservative is within the permitted levels. Several analytical methods have been applied in research studies to determine preservatives in foods include high performance liquid chromatography (HPLC) [7] [8], headspace gas chromatography-flame ionization detector (HS GC-FID) [9], gas chromatography-mass spectrometry [10], and miniature ion trap mass spectrometer [11].

In a previous study we optimized and validated a reliable method based on derivatisation and dispersive liquid-liquid microextraction method, followed by gas chromatography-mass spectrometry (GC-MS). Fast automated Scan/SIM Type (FASST) acquisition was applied to simultaneously determine (qualitative and quantitative analysis) two different classes of preservatives, i.e., carboxylic acid and phenolic compounds in representative pharmaceuticals and cosmetics [12]. FASST is a type of mass acquisition that switches between Scan and SIM mode for a single group during a measurement. As a result, acquisition parameters for both Scan and SIM modes can be specified in the same group. Here we report on the application of the develop method to the analysis of the studied preservatives in two different food products (i.e., soft drink and sauces).

Table 1. Properties of SA, SB, MP and PP.

\begin{tabular}{|c|c|c|c|c|}
\hline & SA & SB & MP & PP \\
\hline IUPAC & 2,4-hexadienoic acid & Sodium benzoate & Methyl-4-hydroxybenzoate & Propyl-4-hydroxybenzoate \\
\hline Formula & $\mathrm{C}_{6} \mathrm{H}_{8} \mathrm{O}_{2}$ & $\mathrm{C}_{7} \mathrm{H}_{5} \mathrm{O}_{2} \mathrm{Na}$ & $\mathrm{C}_{8} \mathrm{H}_{8} \mathrm{O}_{3}$ & $\mathrm{C}_{10} \mathrm{H}_{12} \mathrm{O}_{3}$ \\
\hline M.wt (gm/mole) & 112.13 & 144.11 & 152.15 & 180.20 \\
\hline $\log \mathrm{K}_{\mathrm{ow}}$ & 1.33 & 1.87 & 1.91 & 2.94 \\
\hline \multicolumn{5}{|l|}{ Structure } \\
\hline CAS No. & [22500-92-1] & {$[532-32-1]$} & [99-76-3] & [94-13-3] \\
\hline E-number & E-200 & E-211 & E-218 & E-216 \\
\hline
\end{tabular}




\section{Materials and Methods}

\subsection{Chemicals}

Methylparaben (99\%, MP), propylparaben (99\%, PP), sorbic acid (98\%, SA), and isobutyl chloroformate (99\%, iBCF) were acquired from Merck (Germany). Sodium benzoate ( $99 \%, \mathrm{SB})$, sodium hydroxide $(98 \%, \mathrm{NaOH})$, pyridine $(98 \%, \mathrm{Pyr})$, and chloroform $\left(99.5 \%, \mathrm{CHCl}_{3}\right.$ ) were provided by $\mathrm{BDH}$ (England). Ethanol and acetonitrile were purchased from Sigma-Aldrich (USA). Individual stock solutions of each target analyte at a concentration of $1000 \mu \mathrm{g} / \mathrm{mL}$ were prepared in distilled water and stored at $4^{\circ} \mathrm{C}$. Further dilutions and mixtures were prepared on the day of analysis in distilled water.

\subsection{Food Samples}

Liquid (i.e., soft drink) and semi-solid (i.e., sauces) food samples by global brands were purchased from local Baghdad stores. An approximately $1.0 \mathrm{gm}$ of sauces sample was diluted to $10 \mathrm{~mL}$ with deionized water and then treated with an ultrasonic bath for $10 \mathrm{~min}$ to disperse the aliquot. The sauces sample was then filtered to remove undissolved particles prior to analysis. Whereas, $1 \mathrm{~mL}$ of soft drink was diluted to $10 \mathrm{~mL}$ and degassed for $10 \mathrm{~min}$ in the ultrasonic bath at room temperature. Samples were spiked with $5 \mu \mathrm{g} / \mathrm{mL}$ of the corresponding mixture of the target analytes at different dilution ratio (i.e., 1:50, 1:100, 1:1000, and 1:2000) to evaluate matrix effect of real samples.

\subsection{Derivatization and DLLME Procedures}

The applied method for preparing and extracting iBCF derivatives of the target analytes in foods was adopted from our previous study [12]. Briefly, acylation derivatisation was performed with $30 \mu \mathrm{L}$ of $\mathrm{iBCF}, 30 \mu \mathrm{L}$ of pyridine, and $150 \mu \mathrm{L}$ ethanol, which was followed by DLLME approach to recover the generated derivatives with $1 \mathrm{~mL}$ of $\mathrm{CHCl}_{3}$. After centrifugation, $1 \mu \mathrm{L}$ from the organic phase was injected into the GC-MS. Figure 1 illustrates the applied method.

\subsection{GC-MS Analysis}

Analyses were performed on a Gas Chromatograph (GC 2010Plus) coupled to a Mass Spectrometer (QPMS 2010Ultra), both instruments were made in Shima$\mathrm{dzu} / J a p a n$. The detailed setup parameters for the GC-MS system are shown in Table 2. The GC-MS spectra were evaluated by GCMSsolution v.4 software (Shimadzu, Japan). Target analytes were searched in the National Institute of Standards and Technology (NIST) MS search v.8 library browser and verified by comparing with the authentic standards.

\section{Results and Discussion}

\subsection{Targeted GC-MS Analysis}

According to the combined derivatisation-extraction method that has been optimized in our pervious study, two families of preservatives (i.e., carboxylic acid 


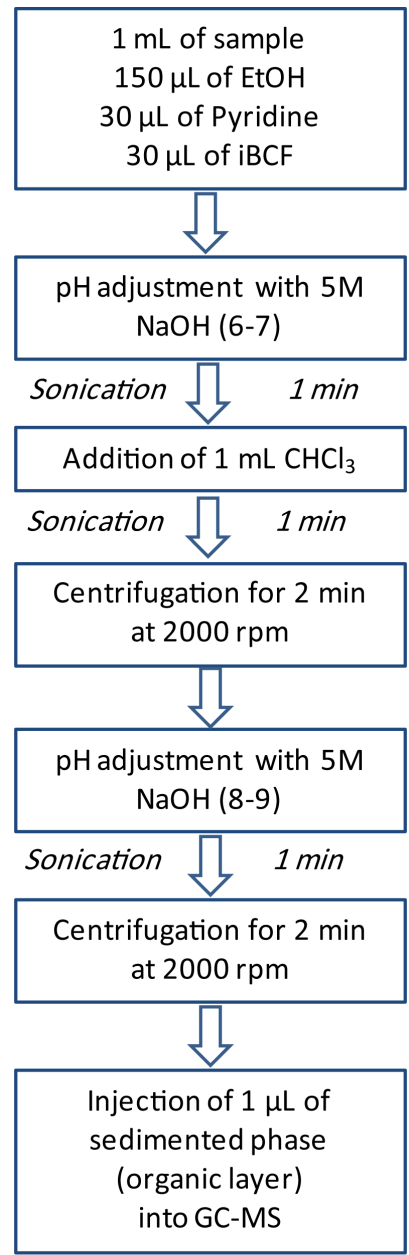

Figure 1. A scheme of the applied method [12].

Table 2. GC-MS setup parameters.

\begin{tabular}{|c|c|c|}
\hline \multirow{3}{*}{$\begin{array}{l}\text { Sample Introduction } \\
\text { (AOC 20i, } \\
\text { Shimadzu, Japan) }\end{array}$} & Mode & Splitless \\
\hline & Injector Temperature & $240^{\circ} \mathrm{C}$ \\
\hline & Injection Volume & $1 \mu \mathrm{L}$ \\
\hline \multirow{5}{*}{$\begin{array}{l}\text { Gas Chromatograph } \\
\text { (GC 2010Plus, } \\
\text { Shimadzu, Japan) }\end{array}$} & Capillary Column & Shimadzu InertCap Wax $(30.0 \mathrm{~m} \times 0.25 \mathrm{~mm} \times 0.25 \mu \mathrm{m}$ film thickness $)$ \\
\hline & Carrier Gas & Helium (99.999\%) \\
\hline & Column Flow Rate & $1.53 \mathrm{~mL} \cdot \mathrm{min}^{-1}$ \\
\hline & Oven Temperature Program & $\begin{array}{l}70^{\circ} \mathrm{C} \text { (held } 3 \mathrm{~min} \text { ), ramped to } 150^{\circ} \mathrm{C} \text { at } 15^{\circ} \mathrm{C} \mathrm{min}^{-1} \text { (held } 2 \mathrm{~min} \text { ), } \\
\text { and a final ramp to } 240^{\circ} \mathrm{C} \text { at } 15^{\circ} \mathrm{C} \mathrm{min}^{-1} \text { (held } 8 \mathrm{~min} \text { ) }\end{array}$ \\
\hline & Run Time & $21.33 \mathrm{~min}$ \\
\hline \multirow{6}{*}{$\begin{array}{l}\text { Mass Spectrometer } \\
\text { (QPMS 2010Ultra, } \\
\text { Shimadzu, Japan) }\end{array}$} & Acquisition Mode & FASST \\
\hline & Mass Range (m/z) & $35-400 \mathrm{amu}$ \\
\hline & Solvent Delay & $6.4 \mathrm{~min}$ \\
\hline & Source Temperature & $200^{\circ} \mathrm{C}$ \\
\hline & Transfer Line Temperature & $240^{\circ} \mathrm{C}$ \\
\hline & Electron Energy & $70 \mathrm{eV}$ \\
\hline
\end{tabular}


and phenolic compounds) were investigated in food samples. As reported before, a tenfold increase in sensitivity has been observed for all studied analytes when compared to those analysed without derivatisation. An improvement in the chromatographic performance, i.e., symmetric peak shape and responses has been observed with the applied method. The two-step derivatisation protocol was performed by applying $\mathrm{pH}$ adjustment to simultaneously detect the carboxylic acid and phenolic compounds in the studied samples. Compound detection was based on FASST acquisition where high sensitivity for the quantitative analysis (SIM mode) and mass spectra for unknown identification (Scan mode) can be achieved. Ions with higher abundance (higher $\mathrm{S} / \mathrm{N}$ ratio) was selected for better sensitivity, whereas, ions with higher $\mathrm{m} / \mathrm{z}$ ratio were chosen for better selectivity. As a result, ions monitored in FASST mode for all derivatives of target analytes were: $\mathrm{m} / \mathrm{z}$ (67), 95, 140 for SA; m/z 77, (105), 122, 150 for BA; m/z 57, 121, (152) for MP; and $\mathrm{m} / \mathrm{z} 57,121$, (138) for PP; the quantifier ions being in brackets (Table 3 ).

During the derivatisation reaction, minor derivatives with a ratio of less than $5 \%$ for all analytes and major derivatives for both classes were generated in the reaction medium. The major derivatives of MP and PP were detected as alkoxycarbonly esters, whereas, alkyl esters were superior for SA and BA (Figure 2). Figure 3 shows the extracted ion chromatograms for the major derivatives of target preservatives that were used for the quantification analysis.

The matrix effect (ME) was evaluated accordingly to the dilution ratios mentioned in section (2.2). Percent recoveries of the target analytes from the samples were generally improved for all analytes. Sauce samples showed a higher percentage of recovery when applying 100-fold dilution, while, 1000-dilution was required to analyse soft drink samples (Figure 4).

Table 3. GC-MS analyses of target analytes as iBCF derivatives.

\begin{tabular}{|c|c|c|c|c|c|c|c|c|c|c|}
\hline Analyte & RT & {$[\mathrm{M}]^{+\bullet}$} & {$[\mathrm{M}-15]^{+}$} & {$[\mathrm{M}-28]^{+}$} & {$[\mathrm{M}-31]^{+}$} & {$[\mathrm{M}-56]^{+}$} & {$[\mathrm{M}-59]^{+}$} & {$[\mathrm{M}-72]^{+}$} & {$[\mathrm{M}-100]^{+}$} & Other $\mathrm{m} / \mathrm{z}$ \\
\hline ES & 7.81 & 140 & 125 & 112 & & & & & & $97,95,67,41$ \\
\hline IS & 8.97 & $168 \mathrm{vs}$ & 153 & & & $113^{*}$ & & & & $95,67,41$ \\
\hline $\mathrm{EB}$ & 9.30 & 150 & & 122 & & & & & & $105,77,51$ \\
\hline IB & 10.63 & ND & & & & $123^{*}$ & & & & $105,77,56,51$ \\
\hline EMP & 15.79 & 224 & & & 193 vs & & & 152 & & $121,93,65,41$ \\
\hline IMP & 16.43 & 252 vs & & & 221 & & & & 152 & $121,93,57,41$ \\
\hline EPP & 16.50 & 252 & & & & & 193 & 180 & & $138,121,93,65,41$ \\
\hline IPP & 17.26 & 280 vs & & & & & 221 & & 180 & $138,121,93,57,41$ \\
\hline
\end{tabular}

ES: ethyl sorbate; IS: isobutyl sorbate; EB: ethyls benzoate; EMP: ethyl methylparaben carbonate; IMP: isobutyl methylparaben carbonate; EPP: ethyl propylparaben carbonate; IPP: isobutyl propylparaben carbonate. ${ }^{\star}$ hydrogen migration and rearrangement; values in bold represent base peak ions; vs: very

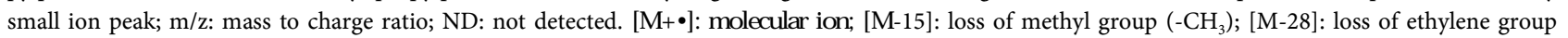
$\left(-\mathrm{C}_{2} \mathrm{H}_{4}\right)$; [M-31]: loss of methoxy group $\left(-\mathrm{OCH}_{3}\right)$; [M-56]: loss of isobutyl group $\left(-\mathrm{C}_{4} \mathrm{H}_{8}\right)$; [M-59]: loss of propoxy group (-OC $\left.\mathrm{H}_{7}\right)$; [M-72]: loss of ethoxycarbonyl group $\left(\mathrm{C}_{3} \mathrm{H}_{4} \mathrm{O}_{2}\right)$; [M-100]: loss of isobutoxycarbonyl group $\left(\mathrm{C}_{5} \mathrm{H}_{8} \mathrm{O}_{2}\right)$. 


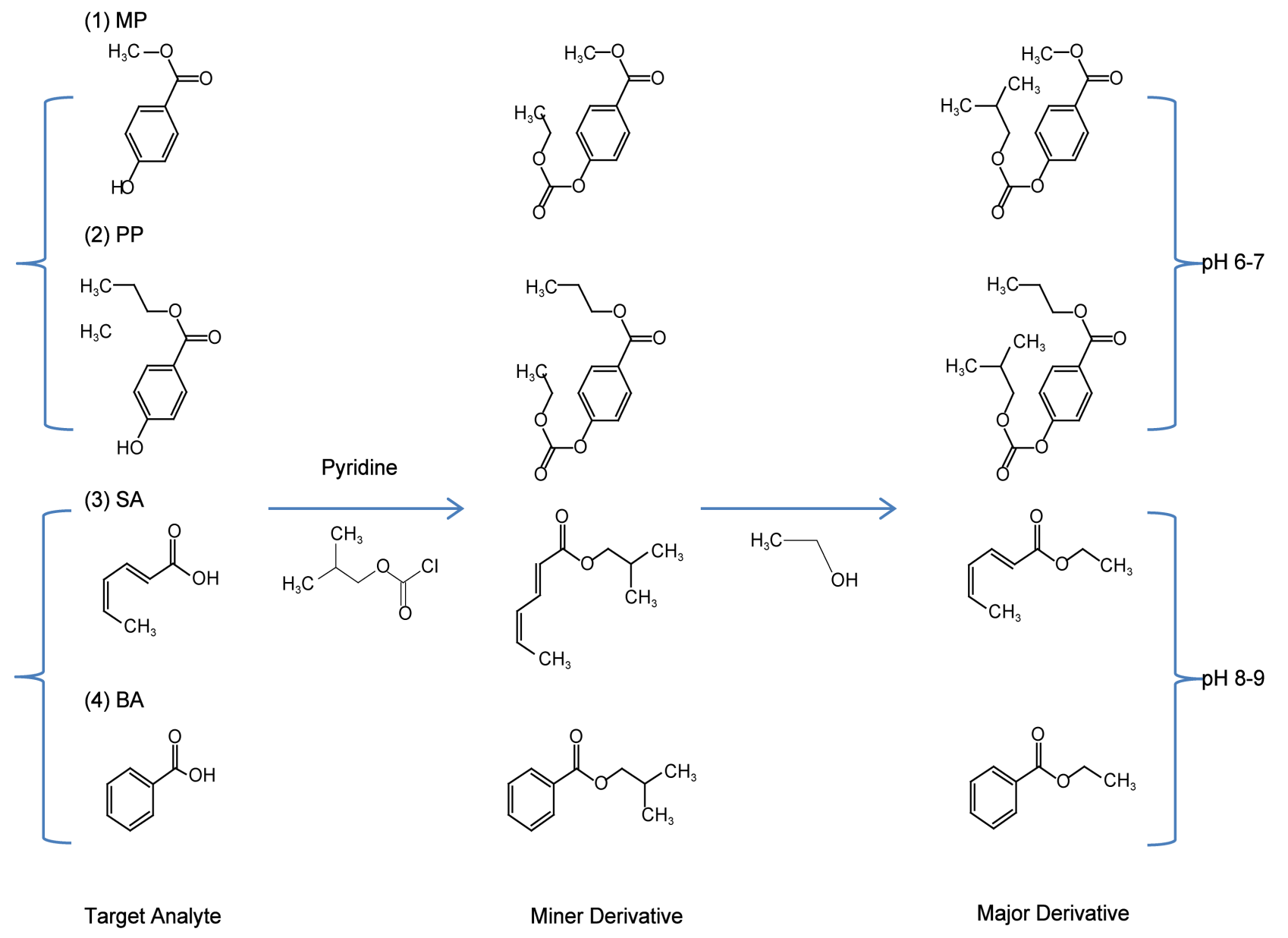

Figure 2. Overall scheme of iBCF derivatisation of four target compounds at two pH medium aqueous system: (1) MP; (2) PP; (3) $\mathrm{SA}$; (4) BA.
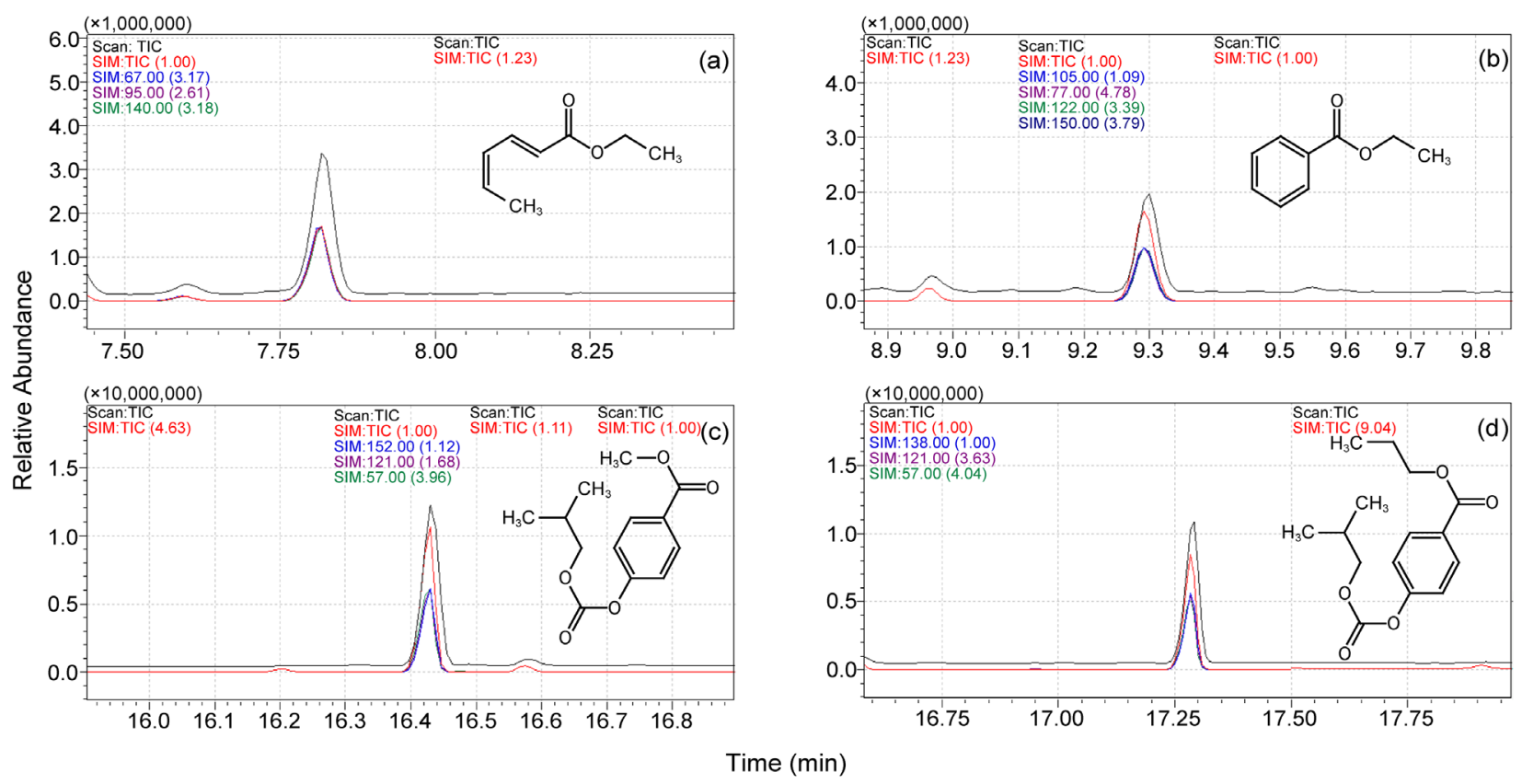

Figure 3. GC-MS (FASST) ion chromatograms of derivatised: SA (a); BA (b) characterized as ethyl esters; MP (c); and PP (d) characterized as isobutoxycarbonyl esters. 


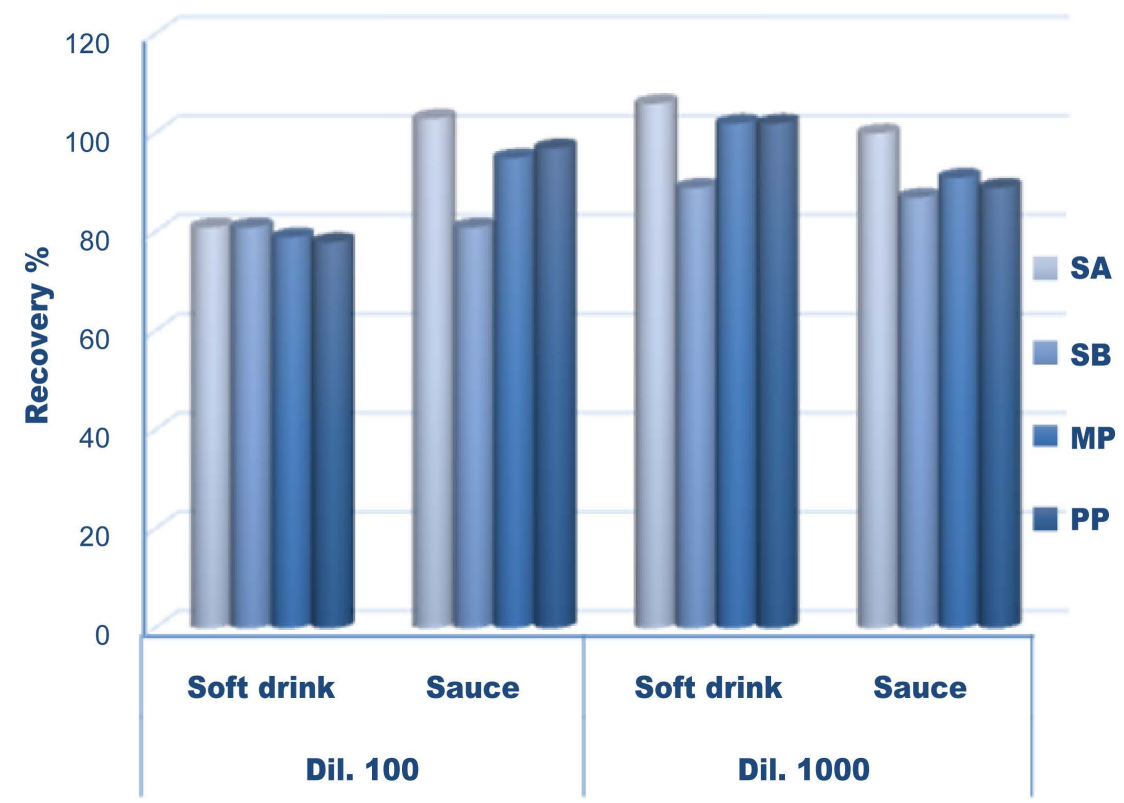

Figure 4. Recovery of target preservatives (SA, BA, MP, and PP) spiked into food samples after dilution of $1: 100$ and $1: 1000$.

\subsection{Application to Real Samples}

The applicability of the method to real samples was evaluated by the determination of the target analytes to accurately quantify the target preservatives in the selected samples (i.e., soft drink and sauce). The target analytes were determined according to the standard addition method where real samples spiked at three concentration levels $(0.5,1.0$, and $5.0 \mu \mathrm{g} / \mathrm{mL})$. Each sample was analyzed in triplicate, and the mean values of the concentration of SA were $210 \mu \mathrm{g} / \mathrm{mL}$ and 1000 $\mu \mathrm{g} / \mathrm{mL}$ in soft drink and sauce samples, respectively. On the other hand, BA (226 $\mu \mathrm{g} / \mathrm{mL}$ ) was only detected in soft drink, whereas, parabens were not found in any sample collected from the local stores. The added preservatives that are labelled on the sample must not exceed the maximum allowed limit. As reported in food survey of benzoates and sorbates in soft drinks, $150 \mu \mathrm{g} / \mathrm{mL}$ is the maximum permitted level for $\mathrm{BA}$, whereas, $300 \mu \mathrm{g} / \mathrm{mL}$ for SA (as a single additive) and 250 $\mu \mathrm{g} / \mathrm{mL}$ (as a combined additive with $\mathrm{BA}$ ) are the maximum allowed level [13]. Benzoate is largely used in beverage industry because of the high concentration of fructose corn syrup in soft drinks including water-based, flavoured, and carbonated drinks [14]. As a result, benzoate containing soft drinks account for the highest human consumption in the world. Also, chemical changes can occur to BA due to the presence of other chemical ingredients in a sample resulting in the generation of carcinogenic benzene. Therefore, food control systems are essential for imported and exported foods to ensure health and safety of domestic consumers, and to maintain consumer confidence in the food system.

\subsection{Non-Targeted GC-MS Analysis}

In addition to the main objective targeted analysis of the commonly used preservatives in food, non-targeted approach of the applied samples was achieved 
by only a single run. In another word, the key benefit of this multi-analysis approach was the non-targeted analysis that allowed screening of unknown substances in the samples without authentic standards. The chromatogram of Figure 5 verifies that the used method can be applied for quantitative and monitoring analysis. The ingredients (citric acid, malic acid) found in soft drinks were putatively characterised as ethyl derivatives (Figure 6).

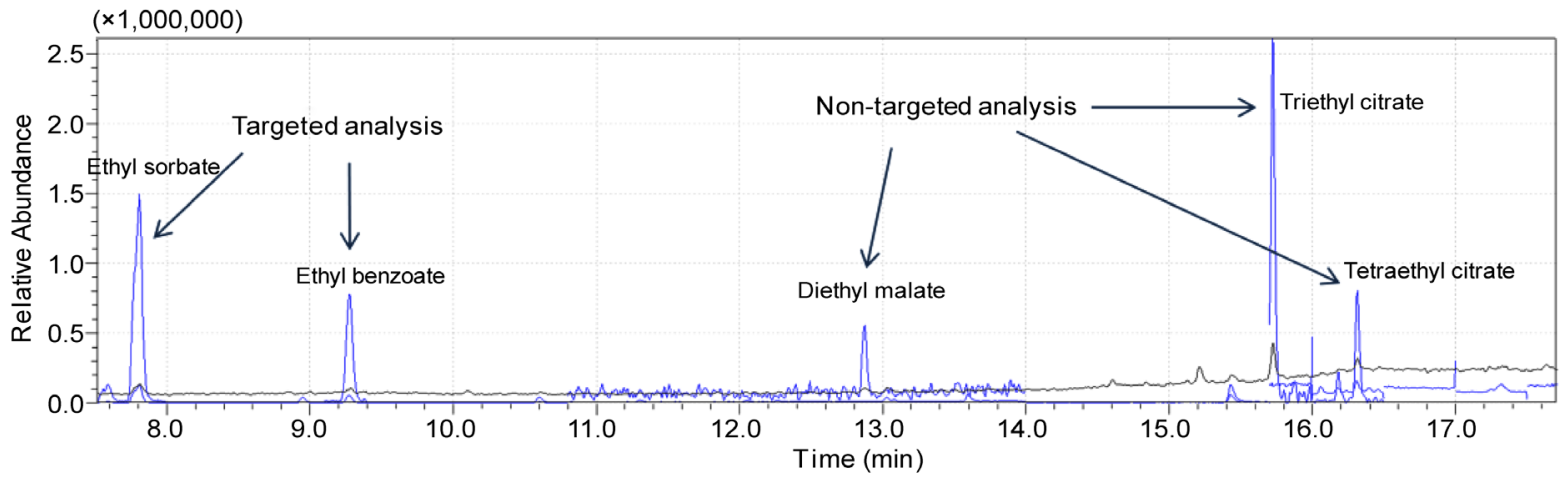

Figure 5. Resultant ion chromatogram from the GC-MS (FASST) analysis of soft drink for the added ingredients.
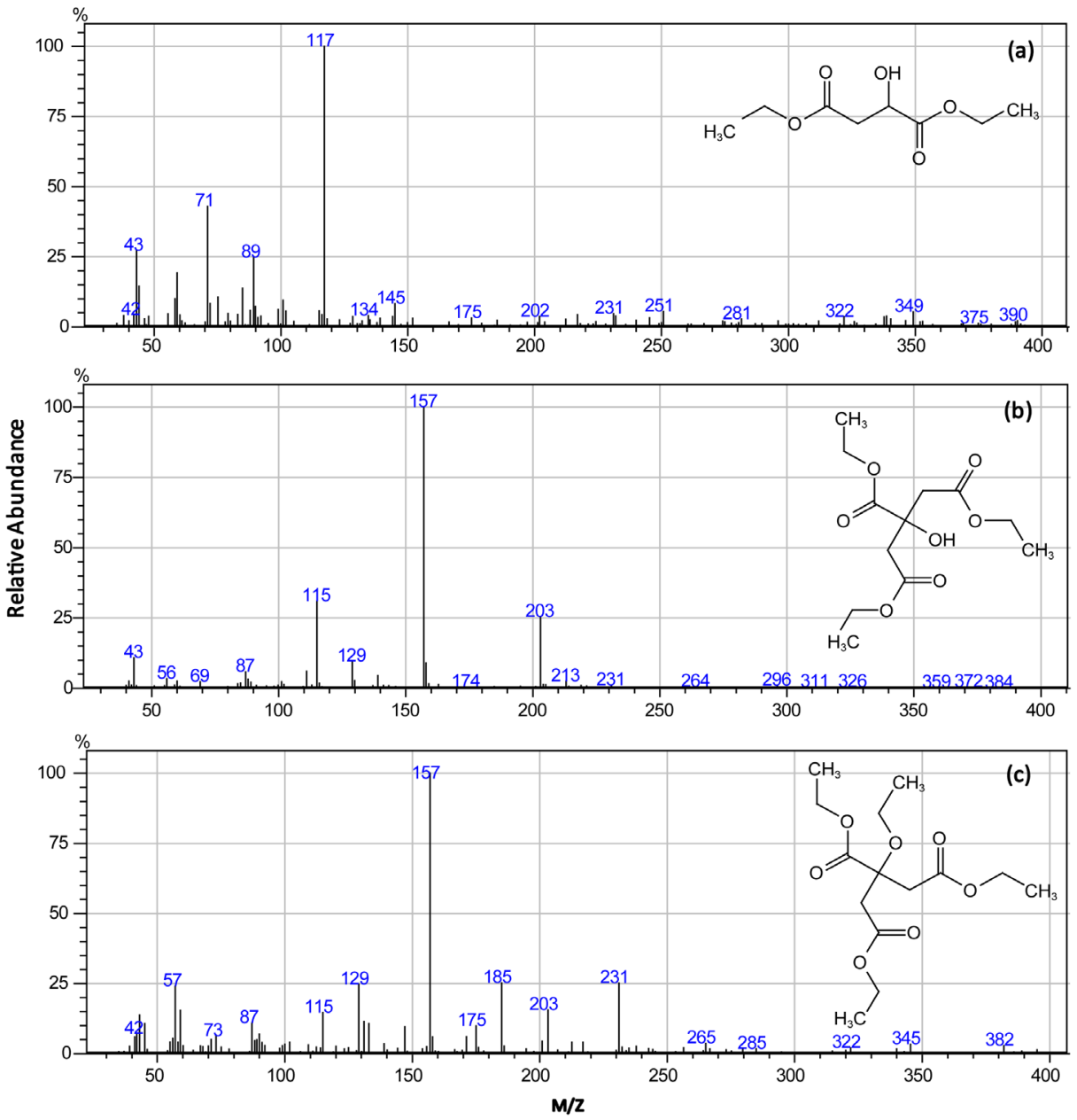

Figure 6. Mass spectra for three ingredients found in soft drink samples that putatively identified as (a) diethyl malate, (b) triethyl citrate, and (c) tetraethyl citrate at RT of $12.87 \mathrm{~min}, 15.72 \mathrm{~min}$, and $16.31 \mathrm{~min}$, respectively. 
In comparison to previous studies, the applied method demonstrated the convenient usage of isobutyl chloroformate derivatisation to qualitative and quantitative analysis of various ingredient compounds present in different food matrices by GC-MS in FASST mode. FASST acquisition allows improved sensitivety and selectivity of analytes as well as minizes sample matrix interferences. The application of this method along with appropriate standard addition with sample dilution approach proved that matrix effects were strongly demininshed for two classes of preservatives in two different matrices of real samples, and therefore will find a wide-range application for routine analysis in food control laboratories.

\section{Conclusion}

The method based on derivatization-DLLME followed by GC-MS FASST for the simultaneous determination of the commonly used preservatives (i.e., SA, BA, MP and PP) in food samples has been applied. The present study demonstrated the capability of performing this multicomponent analytical method conveniently in laboratory-based quality control.

\section{Acknowledgements}

The authors gratefully thank to the Mass Spectrometry Service Laboratory at the University of Al-Mustansiriya/College of Science/Department of Chemistry, for the permission to conduct the GC-MS experiments and would also like to thank Dr Unber Shafique for proofreading the manuscript.

\section{References}

[1] Martin, Y.C. (1996) Exploring QSAR: Hydrophobic, Electronic, and Steric Constants C. Hansch, A. Leo, and D. Hoekman. American Chemical Society, Washington, DC. 1995 . Xix +348 pp. $22 \times 28.5$ cm. Exploring QSAR: Fundamentals and Applications in Chemistry and Biology. C. Hansch and A. Leo. American Chemical Society, Washington, DC. 1995. Xvii + 557 pp. $18.5 \times 26 \mathrm{~cm}$. ISBN 0-8412-2993-7 (set). \$99.95 (set). Journal of Medicinal Chemistry, 39, 1189-1190. https://doi.org/10.1021/jm950902o

[2] Angelov, T., Vlasenko, A. and Tashkov, W. (2007) HPLC Determination of pKa of Parabens and Investigation on their Lipophilicity Parameters. Journal of Liquid Chromatography \& Related Technologies, 31, 188-197. https://doi.org/10.1080/10826070701738787

[3] Routledge, E.J., et al. (1998) Some Alkyl Hydroxy Benzoate Preservatives (Parabens) Are Estrogenic. Toxicology and Applied Pharmacology, 153, 12-19.

[4] Tfouni, S.A.V. and Toledo, M.C.F. (2002) Determination of Benzoic and Sorbic Acids in Brazilian Food. Food Control, 13, 117-123.

[5] Mota, F.J.M., et al. (2003) Optimisation of Extraction Procedures for Analysis of Benzoic and Sorbic Acids in Foodstuffs. Food Chemistry, 82, 469-473.

[6] Soni, M.G., Carabin, I.G. and Burdock, G.A. (2005) Safety Assessment of Esters of p-Hydroxybenzoic Acid (Parabens). Food and Chemical Toxicology, 43, 985-1015.

[7] Yang, P., Ren, H., Qiu, H., Liu, X. and Jiang, S. (2011) Determination of Four Trace Preservatives in Street Food by Ionic Liquid-Based Dispersive Liquid-Liquid Mi- 
cro-Extraction. Chemical Papers, 65, 747-753.

[8] Sugiura, J. and Nakajima, M. (2017) Simultaneous Determination of Nine Preservatives in Food by Liquid Chromatography with the Aid of Coagulant in the CleanUp Process. Food Additives \& Contaminants. Part A, 1-10. https://doi.org/10.1080/19440049.2017.1293302

[9] Dong, C., Mei, Y. and Chen, L. (2006) Simultaneous Determination of Sorbic and Benzoic Acids in Food Dressing by Headspace Solid-Phase Microextraction and Gas Chromatography. Journal of Chromatography A, 1117, 109-114.

[10] Djatmika, R., et al. (2016) Determination of Paraben Preservatives in Seafood Using Matrix Solid-Phase Dispersion and On-Line Acetylation Gas ChromatographyMass Spectrometry. Journal of Chromatography B, 1036-1037, 93-99.

[11] Ma, Q., et al. (2016) Direct Identification of Prohibited Substances in Cosmetics and Foodstuffs Using Ambient Ionization on a Miniature Mass Spectrometry System. Analytica Chimica Acta, 912, 65-73.

[12] Eman Wajih Ameen, R.A.-S. (Submitted) A Novel Gas Chromatography-Mass Spectrometry (Fast Automated Scan/SIM Type) Approach for the Analysis of Preservatives.

[13] (2008) Food Standards Agency, Food Surveys, Survey of Benzoates and Sorbates in Soft Drinks.

http://tna.europarchive.org/20140306205048/http://www.food.gov.uk/science/resea rch/surveillance/fsisbranch2008/fsis0608

[14] World Health Organization (2000) Concise International Chemical Assessment Document No. 26 on Benzoic Acid and Sodium Benzoate. Geneva, Switzerland.

\section{Submit or recommend next manuscript to SCIRP and we will provide best service for you:}

Accepting pre-submission inquiries through Email, Facebook, LinkedIn, Twitter, etc. A wide selection of journals (inclusive of 9 subjects, more than 200 journals)

Providing 24-hour high-quality service

User-friendly online submission system

Fair and swift peer-review system

Efficient typesetting and proofreading procedure

Display of the result of downloads and visits, as well as the number of cited articles

Maximum dissemination of your research work

Submit your manuscript at: http://papersubmission.scirp.org/

Or contact ajac@scirp.org 